\title{
Research on Indicator System of Construction Project Comprehensive Performance Management and Evaluation: Based On Combination Weight and TOPSIS
}

\author{
Tao $\mathrm{Li}^{\mathrm{a}}$ and Hao Liu ${ }^{\mathrm{b}, *}$ \\ School of Economics and Management, North China Electric Power University, \\ Beijing 102206, People's Republic of China \\ a442508263@qq.com; ${ }^{b}$ liuhao1989610@163.com
}

\begin{abstract}
Currently, the scope of the traditional indicator system for performance evaluation of construction project is much broader. But the indicators are mostly involved only in quality, schedule, and environmental goals of the project. In other words, it only focuses on considering the level of performance that only a few large projects in progress goals, without taking into account of the impact on the overalhperformance level caused by the employees involved in the project and project management level of internal management of the project, which cannot meet the requivements for performance evaluation. Therefore, this article, from the view of the traditional project performance evaluation, through the introduction of financial indicators, indicatons of internal, learning and development indicators, suggests a new Comprehensive performance evaluation index system for construction projects. Based on the newl built comprehensive performance evaluation index system of construction project, the collected project data by the author of this paper will be processed andanalyzed. According to the characteristics of the index system and data rules, together with the intcoduction of a combination of indicators of empowerment evaluation method and TOPSIS method, the three construction project performance level is evaluated comprehensively in order to verify the rationality and practicality of the proposed construction project of comprehensive performance rating system. The results of this researeh show that the proposed project overall level of performance evaluation method is feasible, and it can be employed to do more comprehensive performance evaluation of the construction project, which provides new ideas and keference for the comprehensive evaluation of the level of performance of construction projects
\end{abstract}

Keywords: comprehensive performance; evaluation methods; index system; combination wetght; TOPSIS; index system

\section{Introduction}

With the further expansion in the construction field, more and more enterprises are faced with the obvious problems of how to fully enhance the project performance management and, at the same time, make a reasonable and holistic evaluation on the project performance level, and other issues as well. Comprehensive performance evaluation of the project is not only the key to improving the overall management of the project, but also an important measure to improve the construction of their own level of performance. Traditional indicators of performance evaluation system involves mostly just in quality, schedule, and environmental goals of the project, that is to say, it only considers the level of performance that only a few large projects in progress goals, without taking into account of the impact on the overall performance level caused by the staff involved 
in the project and project management level of internal management of the project, which cannot meet the requirements for the performance evaluation.

With the rapid development of performance evaluation theory and practice, the evaluation processes of enterprise performance and project performance have made great progress. The enterprise performance evaluation has gradually improved from former financial evaluation to comprehensive evaluation which focuses on both financial indicators and other enterprise indicators. The most representative comprehensive evaluation methods are balanced score card-BSC[1] and key performance indicators-KPI[2] Meanwhile, the project is improving the level of performance evaluation, the target range is not only involved in aspects of the project schedule, quality, safety, and environment, but also contribute to keep the project on business development point of view. E.K. Zavadskasn, etc [3] established project performance evaluation index system includes not only the traditional project performance indicators, also includeed project profitability, revenue management and other aspects. Wang Tingjing and Lai Changbing [4]established indicator system of project performance from the aspects of economic benefits, socioeconomic impact, operation, environment impact, but indicators related to project progress, its cost and quality were not included. Besides the indicator system was improving towards project cost and employed attitude [5], which also exceeded the purpose scopes of traditional projectperformance evalyation.

In summary, current at the time of the evaluation of project performance evaluation index system constructed system compared with traditional indicators have great development, but the main index system to expand the company's financial and internal staff point of view, involving content still has some limitations. Therefore, this article is not only isola fed from the traditional indicators of project performance evaluation system, but also the introduction of innovative financial indicators, indicators of internal processes, learning and development indicators, the establishment of a new comprehensive performance evaluation of the project to ensure project performance evaluation for comprehensive, reasonable. Then quantitative indicators and qualitative indicators of quantitative data collection process. According to the index system characteristics and data rules, select the calculation of each index combination weighting method Entropy Law and the characteristic yane method based on the weight, and then select the ideal point method for comprehensive evaluation of the project. Finally, collecting three performance indicators in the construction project data to verify the scientific paper establishes the index system through examples, rationality, to provide a method of reference for a comprehensive evaluation of the level of performance of construction profects.

\section{Establishment of Indicator System and Collection of Indicators Data 2.1. Establishing Indicator System}

In order to ensure the objectivity and reasonableness of project performance evaluation, this paper establishes indicator system from the aspects of enterprise performance and project performance, in which enterprise performance indicators are from common indicator systems of enterprise performance evaluation ${ }^{[4]}$, and project performance indicators are from some project under construction ${ }^{[6]}$. To ensure the comprehensiveness and simplicity, expert consultation and multivariate statistical methods are applied to simply the redundant indicators and indicators that correlate little with evaluation purpose, and the indicator system after reduction is shown in Table 2-1. 
Table 2-1. Indicator System of Construction Project Performance Evaluation

\begin{tabular}{|c|c|c|c|c|}
\hline First class & Second class & \multicolumn{3}{|c|}{ Third class } \\
\hline \multirow{13}{*}{$\begin{array}{l}\text { Indicator } \\
\text { system of } \\
\text { construction } \\
\text { project } \\
\text { performance } \\
\text { evaluation } \\
\text { (O) }\end{array}$} & \multirow{2}{*}{ finance $\left(\mathrm{A}_{1}\right)$} & \multicolumn{3}{|c|}{ income satisfaction of staff $\left(\mathrm{B}_{11}\right)$} \\
\hline & & \multicolumn{3}{|c|}{ capital utilization $\left(\mathrm{B}_{12}\right)$} \\
\hline & \multirow{2}{*}{ internal process $\left(A_{2}\right)$} & \multicolumn{3}{|c|}{ administration innovation $\left(\mathrm{B}_{21}\right)$} \\
\hline & & \multicolumn{3}{|c|}{ management quality $\left(\mathrm{B}_{22}\right)$} \\
\hline & \multirow{2}{*}{$\begin{array}{c}\text { learning and } \\
\text { development }\left(\mathrm{A}_{3}\right)\end{array}$} & \multicolumn{3}{|c|}{ staffs learning attitude $\left(\mathrm{B}_{31}\right)$} \\
\hline & & \multicolumn{3}{|c|}{ perfect degree of incentive mechanism $\left(B_{32}\right)$} \\
\hline & & \multicolumn{3}{|c|}{$\begin{array}{c}\text { timeliness of material, equipment and } \\
\text { construction units }\left(\mathrm{B}_{41}\right)\end{array}$} \\
\hline & & \multirow{2}{*}{\multicolumn{3}{|c|}{$\begin{array}{c}\text { completion of construction schedule plan }\left(\mathrm{B}_{42}\right) \\
\text { complete construction data }\left(\mathrm{B}_{4}\right)\end{array}$}} \\
\hline & & & & \\
\hline & $\operatorname{cost}\left(\mathrm{A}_{5}\right)$ & \multicolumn{3}{|c|}{ budget and final accounts deviationgte $\left(\mathrm{B}_{51}\right)$} \\
\hline & \multicolumn{4}{|l|}{ technique $\left(\mathrm{A}_{6}\right)$} \\
\hline & \multirow[t]{2}{*}{ quality $\left(\mathrm{A}_{7}\right)$} & \multicolumn{3}{|c|}{$\begin{array}{l}\text { The quality qualification rate of raw materials } \\
\text { and equipment }\left(\mathrm{B}_{72}\right)\end{array}$} \\
\hline & & \\
\hline \multicolumn{2}{|c|}{ 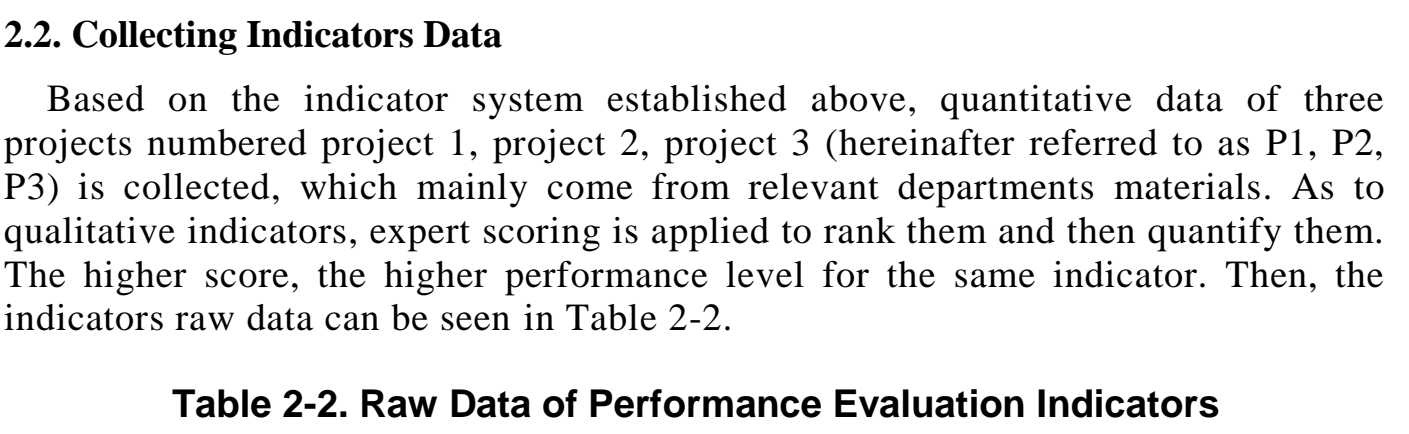 } & & & \\
\hline indicator & units & P1 & $\mathrm{P} 2$ & P3 \\
\hline & $\%$ & 76 & 87 & 84 \\
\hline 1012 & $\%$ & 31 & 40 & 26 \\
\hline $\mathrm{B}_{21}$ & point & 3.8 & 4.3 & 3.2 \\
\hline $\mathrm{B}_{22}$ & point & 3.1 & 3.4 & 4.2 \\
\hline $\mathrm{B}_{31}$ & point & 2.1 & 3.3 & 4.0 \\
\hline $\mathrm{B}_{32}$ & point & 3.8 & 4.2 & 3.6 \\
\hline $\mathrm{B}_{41}$ & $\%$ & 90 & 87 & 72 \\
\hline $\mathrm{B}_{42}$ & $\%$ & 81 & 89 & 76 \\
\hline
\end{tabular}




\begin{tabular}{ccccc}
\hline $\mathrm{B}_{43}$ & $\%$ & 87 & 85 & 79 \\
$\mathrm{~B}_{51}$ & $\%$ & 18 & 9 & 16 \\
$\mathrm{~B}_{52}$ & $\%$ & 75 & 86 & 88 \\
$\mathrm{~B}_{61}$ & $\%$ & 80 & 91 & 84 \\
$\mathrm{~B}_{62}$ & $\%$ & 90 & 95 & 87 \\
$\mathrm{~B}_{71}$ & $\%$ & 95 & 92 & 90 \\
$\mathrm{~B}_{72}$ & $\%$ & 93 & 97 & 85 \\
$\mathrm{~B}_{81}$ & million RMB & 1.24 & 0.97 & 1.35 \\
$\mathrm{~B}_{82}$ & $0-1$ & 0.72 & 0.88 & 0.90 \\
\hline
\end{tabular}

\section{Models and Methods}

\subsection{Processing of Indicators Data}

(1) Unification method

According to the indicator system established in this paper, the indicators including income satisfaction of staff, capital utilization, administration innovation, management quality, staffs' learning attitude, perfect degree of incentive mechanism, timeliness of material, equipment and constuuction units, completion of construction schedule plan, complete constructiondata, reduction rate of project cost, contract compliance rate, resolution rate of technical problem, passing rate of project quality, the quality quafication rate of raw materials and equipment, environmental assessment level are benecit indicators; budget and final accounts deviation rate, environmental protection input cost indicators.

Cost indicators are tansferred into benefit indicators in this paper. The transfer formula is shown as $M-M-x$, where $M$ is the set upper bound of $x$.

(2) Non-dimensional method

When evaluang the project performance level, different dimensions of different indicators makes it hard for the comprehensive evaluation ${ }^{[7]}$. Then, nondimensional method is appled to unify the indicators dimensions, where efficacy coefficient is introduced in this paper ${ }^{[8]}$. The formula of efficacy coefficient is shown below:

$$
x_{i j}^{*}=c+\frac{x_{i j}-m_{j}}{M_{j}-m_{j}} \times d
$$

Where, $M_{j}, m_{j}$ respectively represent maximum and minimum values of each indicator: $c$ and $d$ are known constants, which make the numbers for transformation translate and zoom. The $c$ and $d$ are respectively valued 60 and 40 in this paper.

\subsection{Eigenvalue Method}

Eigenvalue method is used for determining indicators weights by establishing evaluation matrixes and comparing evaluation indicators. Firstly, evaluation matrix A is established, and the eigenvector of matrix A can be calculated by the following formula $(A-\lambda E) x=0$, where $\lambda$ is the root of equation $|A-\lambda E|=0$, and then the indicators weights sequencing can be obtained. The eigenvector corresponding to the maximum eigenvalue of matrix $\mathrm{A}$ is the weight vector wanted. However, this method needs examining consistency. Consistency indicator $C I$ can be calculated 
with the following formula $C I=\left(\lambda_{\max }-m\right) /(m-1)$, where $m$ represents the matrix order. The average random consistency $R I$ meets demands of the Table 3-1.

Table 3-1. Average Random Consistency RI

\begin{tabular}{cccccccccc}
\hline Order & 1 & 2 & 3 & 4 & 5 & 6 & 7 & 8 & 9 \\
RI & 0 & 0 & 0.58 & 0.9 & 1.12 & 1.24 & 1.32 & 1.41 & 1.45 \\
\hline
\end{tabular}

The random consistency rate $C R$ can be calculated with formula $C R=C I / R I$. When $C R$ is lower than 0.10 , the judgment matrix has satisfied consistency; or the judgment matrix need adjusting, until it has satisfied consistency.

\subsection{Entropy Weight Method}

Entropy weight method is used to determine the indicators weights based on information load of each indicator ${ }^{[9]}$. Here establishes matrix $\mathrm{R}=\left(x_{\mathrm{ij}}\right)_{\mathrm{m}^{*} \mathrm{n}}$, nn which $x_{i j}$ represents the $i$ th indicator attribute corresponding to $j$ th item. The detailed procedure of the entropy weight method is given below:

(1) Contribution degree

$$
p_{i j}=x_{i j} / \sum_{i=1}^{n} x_{i j}
$$

Where, $p_{i j}$ represents the contribution degree of the $j$ th item corresponding to $i$ th indicator attribute.

(2) Entropy

Entropy $e_{i}$ is the total contribution of all the items to ith indicator:

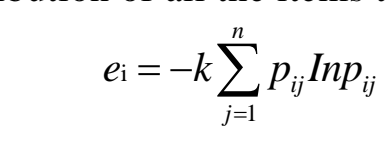

Where, constant $k$ can be calculated by formula $k=1 /$ Inn .

(3)Difference coefficient.

$g_{i}$ represents contribution difference of each item corresponding to the $i$ th indicator.

(4)Indicators weights

$$
g_{i}=1-e_{i}
$$

The entropy weight of the $j$ th indicator can be obtained by the following formula:

\subsection{Combination Weight Method}

$$
w_{i}=\frac{g_{i}}{\sum_{i=1}^{m} g_{i}}
$$

In Corder to avoid the influence of experts' subjective preferences in subjective weight, and uncontrolled weighting result in objective weight, the combination weight is applied to determine the indicators weights ${ }^{[10]}$. The weight vector by eigenvalue method is shown as $w^{\prime}=\left(w_{1}^{\prime}, w_{2}^{\prime}, \cdots, w_{n}^{\prime}\right)^{T}$, and the weight vector by entropy weight method is shown as $w^{\prime \prime}=\left(w_{1}^{\prime \prime}, w_{2}^{\prime \prime}, \cdots, w_{n}^{\prime \prime}\right)^{T}$. Then the combination weight of each indicator can be calculated with the following formula:

$$
w=k_{1} * w^{\prime}+k_{2} * w^{\prime \prime}
$$

Where, $k_{1}+k_{2}=1$ and $k_{1}, k_{2}>0$. 


\subsection{TOPSIS}

TOPSIS is originated in discrimination problems of multivariate statistical analysis [11]. The detailed procedures of TOPSIS are shown below:

(1)Standard decision matrix

Based on the indicators data after processing in Table 5-1, the standard decision matrix $\mathrm{T}=\left(t_{\mathrm{ij}}\right)_{\mathrm{m} * \mathrm{n}}$ can be established.

(2) Weighted decision matrix

Based on the indicators combination weight vector $W=\left(w_{1}, w 2, \ldots, w_{\mathrm{m}}\right)$, the weighted decision matrix can be obtained by the following formula:

$$
X=W T=\left[\begin{array}{cccc}
w_{1} t_{11} & w_{2 t_{12}} & \ldots & w_{n} t_{1 n} \\
w_{1} t_{21} & w_{2 t_{22}} & \ldots & w_{n} t_{2 n} \\
\ldots & \ldots & \ldots & \ldots \\
w_{1} t_{m 1} & w_{2} t_{m 2} & \ldots & w_{n} t_{m n}
\end{array}\right]
$$

Where, $w_{j}$ is the weight of the $j$ th indicator and $\sum_{j=1}^{n} w_{j}=1$.

(3)Positive and negative ideal points

In the weighted decision matrix, the positive 10eal point $x^{+}$is a rector composed of maximum number of each column; the negat ve ideal point $x^{-}$is a vector composed of minimum number of each column, that is, $x^{+}$and $x^{-}$meet the requirements below:

$$
\begin{gathered}
x^{+}=\left(x_{1}^{+}, x_{2}^{+}, \ldots, x_{m}^{+}\right), x^{+}=\max \left\{x_{i j}\right\}, j=1,2, \ldots, m \\
x^{-}=\left(x_{1}^{-}, x_{2}^{-}, \ldots, x_{m}\right), x_{j}^{-}=\min \left\{x_{i j}\right\}, j=1,2, \ldots, m
\end{gathered}
$$

(4)Distances with positive andregative ideal solutions

The n-dimension Euclidean distances between evaluated object and positive, negative ideal points are shown by $y_{1}^{+}$and $y_{\mathrm{i}}^{-}$, which are calculated with the following formulas:

(5) Similarities with positive ideal point

$$
\begin{aligned}
& y_{\mathrm{i}}=\sqrt{\sum_{j=1}^{m}\left(\mathrm{x}_{i j}-\mathrm{x}_{j}^{+}\right)}, \quad i=1,2, \ldots, n \\
& y_{\mathrm{i}}^{-}=\sqrt{\sum_{j=1}^{m}\left(\mathrm{x}_{i j}-\mathrm{x}_{j}^{-}\right)}, \quad i=1,2, \ldots, n
\end{aligned}
$$

Similarities with positive ideal point can be obtained by the following formula:

$$
C_{i}=\frac{y_{i}^{-}}{y_{i}^{+}+y_{i}^{-}}
$$

It is obvious that the larger $C_{i}$ is, the longer distance between evaluated object and negative ideal solution and shorter distance between evaluated object and positive ideal solutions are. Then, rank the similarities of all the objects and select the best evaluated object.

\section{Results}

\subsection{Indicators Data Processing}

When conducting unification of indicators data, $M_{51}$ and $M_{81}$ are respectively valued 1.40 million and $100 \%$. Then based on the unification result, the efficacy 
coefficient method is applied to unify the indicators dimensions. The processing result is shown in Table 4-1.

Table 4-1. Processing Result of Indicators Data

\begin{tabular}{ccccccc}
\hline \multirow{2}{*}{ indicators } & & unification & \multicolumn{3}{c}{ non-dimensions } \\
& $\mathrm{P} 1$ & $\mathrm{P} 2$ & $\mathrm{P} 3$ & $\mathrm{P} 1$ & $\mathrm{P} 2$ & $\mathrm{P} 3$ \\
\hline $\mathrm{B}_{11}$ & 76 & 87 & 84 & 60 & 100 & 89.0909 \\
$\mathrm{~B}_{12}$ & 31 & 40 & 26 & 74.2857 & 100 & 60 \\
$\mathrm{~B}_{21}$ & 3.8 & 4.3 & 3.2 & 81.8182 & 100 & 60 \\
$\mathrm{~B}_{22}$ & 3.1 & 3.4 & 4.2 & 60 & 70.9091 & 100 \\
$\mathrm{~B}_{31}$ & 2.1 & 3.3 & 4 & 60 & 85.2632 & 100 \\
$\mathrm{~B}_{32}$ & 3.8 & 4.2 & 3.6 & 73.3333 & 100 & 60 \\
$\mathrm{~B}_{41}$ & 90 & 87 & 72 & 100 & 93.3333 & 60 \\
$\mathrm{~B}_{42}$ & 81 & 89 & 76 & 75.3846 & 100 & 60 \\
$\mathrm{~B}_{43}$ & 87 & 85 & 79 & 100 & 90 & 60 \\
$\mathrm{~B}_{51}$ & 82 & 91 & 84 & 60 & 100 & 68.8889 \\
$\mathrm{~B}_{52}$ & 75 & 86 & 88 & 60 & 93.8462 & 100 \\
$\mathrm{~B}_{61}$ & 80 & 91 & 84 & 60 & 100 & 74.5455 \\
$\mathrm{~B}_{62}$ & 90 & 95 & 87 & 75 & 100 & 60 \\
$\mathrm{~B}_{71}$ & 95 & 92 & 90 & 100 & 76 & 60 \\
$\mathrm{~B}_{72}$ & 93 & 97 & 85 & 866667 & 100 & 60 \\
$\mathrm{~B}_{81}$ & 0.16 & 0.43 & 0.05 & 71.5790 & 100 & 60 \\
$\mathrm{~B}_{82}$ & 0.72 & 0.88 & 0.9 & 60 & 95.5556 & 100 \\
\hline
\end{tabular}

\subsection{Determining the Indicators Weights}

(1) Indicators weights by eigenyalue method

According to the eigenvalue method, the indicators scores tables of relative importance and weighting result are shown from Table 4-2 to Table 4-10. And the weight of each indicator relative to the first class indicator is calculated, as Table 411 shows.

\section{Táble 4-2. Indicator Weights of Layer O-A}

\begin{tabular}{cccccccccc}
\hline $\mathrm{O}-\mathrm{A}$ & $\mathrm{A}_{1}$ & $\mathrm{~A}_{2}$ & $\mathrm{~A}_{3}$ & $\mathrm{~A}_{4}$ & $\mathrm{~A}_{5}$ & $\mathrm{~A}_{6}$ & $\mathrm{~A}_{7}$ & $\mathrm{~A}_{8}$ & weight \\
\hline $\mathrm{A}_{1}$ & & 1.5 & 0.8 & 0.8 & 0.5 & 0.4 & 0.6 & 0.8 & 0.0902 \\
$\mathrm{~A}_{2}$ & 0.6667 & & 0.7 & 0.6 & 0.4 & 0.5 & 0.8 & 0.9 & 0.0813 \\
$\mathrm{~A}_{3}$ & 1.25 & 1.286 & 1 & 1.25 & 1 & 1.5 & 2 & 1.25 & 0.1585 \\
$\mathrm{~A}_{4}$ & 1.25 & 1.6667 & 0.8 & 1 & 0.8 & 1.25 & 1.5 & 0.5 & 0.1249 \\
$\mathrm{~A}_{5}$ & 2 & 2.5 & 1 & 1.25 & 1 & 1.5 & 1.25 & 1 & 0.1653 \\
$\mathrm{~A}_{6}$ & 2.5 & 2 & 0.6667 & 0.8 & 0.6667 & 1 & 0.8 & 0.5 & 0.1164 \\
$\mathrm{~A}_{7}$ & 1.6667 & 1.25 & 0.5 & 0.6667 & 0.8 & 1.25 & 1 & 0.8 & 0.1129 \\
$\mathrm{~A}_{8}$ & 1.25 & 1.1111 & 0.8 & 2 & 1 & 2 & 1.25 & 1 & 0.1505 \\
\hline
\end{tabular}

The maximum eigenvalue $\lambda$ max of judgment matrix is 8.2641 , the value of Consistency indicator $C I 0.0377$, the value of random consistency $R I 0.0267$, and the matrix has satisfied consistency.

Table 4-3. Indicators Weights of Layer A1-B

\begin{tabular}{cccccc}
\hline $\mathrm{A}_{1}$ & $\mathrm{~B}_{11}$ & $\mathrm{~B}_{12}$ & weight & $\lambda_{\max }$ & test \\
\hline $\mathrm{B}_{11}$ & 1 & 0.8 & 0.4444 & 2 & $\mathrm{CI}=0 ;$ \\
$\mathrm{B}_{12}$ & 1.25 & 1 & 0.5556 & 2 & satisfied \\
\hline
\end{tabular}


Table 4-4. Indicators Weights of Layer A2-B

\begin{tabular}{cccccc}
\hline $\mathrm{A}_{2}$ & $\mathrm{~B}_{21}$ & $\mathrm{~B}_{22}$ & weight & $\lambda \max$ & test \\
\hline $\mathrm{B}_{21}$ & 1 & 0.85 & 0.4595 & 2 & $\mathrm{CI}=0 ;$ \\
$\mathrm{B}_{22}$ & 1.1764 & 1 & 0.5405 & 2 & satisfied \\
\hline
\end{tabular}

Table 4-5. Indicators Weights of Layer A3-B

\begin{tabular}{cccccc}
\hline $\mathrm{A}_{3}$ & $\mathrm{~B}_{31}$ & $\mathrm{~B}_{32}$ & weight & $\lambda_{\max }$ & Test \\
\hline $\mathrm{B}_{31}$ & 1 & 1.2 & 0.5455 & 2 & $\mathrm{CI}=0 ;$ \\
$\mathrm{B}_{32}$ & 0.8333 & 1 & 0.4545 & 2 & satisfied \\
\hline
\end{tabular}

Table 4-6 Indicators Weights of Layer A4-B

\begin{tabular}{ccccccc}
\hline $\mathrm{A}_{4}$ & $\mathrm{~B}_{41}$ & $\mathrm{~B}_{42}$ & $\mathrm{~B}_{43}$ & weight & $\lambda$ max & test \\
\hline $\mathrm{B}_{41}$ & 1 & 1.5 & 2 & 0.4568 & & $\mathrm{CI}=0.0051 ;$ \\
$\mathrm{B}_{42}$ & 0.6667 & 1 & 1.8 & 0.3366 & 3.0101 & $\mathrm{CR}=0.0871 ;$ \\
$\mathrm{B}_{43}$ & 0.5 & 0.5556 & 1 & 0.2067 & & Satisfied \\
\hline
\end{tabular}

Table 4-7. Indicators Weights of $\triangle$ aye $A 5-B$

\begin{tabular}{cccc|cc}
\hline $\mathrm{A}_{5}$ & $\mathrm{~B}_{51}$ & $\mathrm{~B}_{52}$ & weight & $\lambda$ max & test \\
\hline $\mathrm{B}_{51}$ & 1 & 0.7 & 0.4118 & 2 & $\mathrm{CI}=0 ;$ \\
$\mathrm{B}_{52}$ & 1.4286 & 1 & 0.5882 & & satisfied \\
\hline
\end{tabular}

Table 4-8. Indicators Weights of Layer A6-B

\begin{tabular}{cccccc}
\hline $\mathrm{A}_{6}$ & $\mathrm{~B}_{61}$ & $\mathrm{~B}_{62}$ & weight & $\lambda$ max & test \\
\hline $\mathrm{B}_{61}$ & 1 & 1.2931 & 0.5639 & 2 & $\mathrm{CI}=0 ;$ \\
$\mathrm{B}_{62}$ & 0.7733 & 1 & 0.4361 & 2 & satisfied \\
\hline
\end{tabular}

Table 4-9. Indicators Weights of Layer A7-B

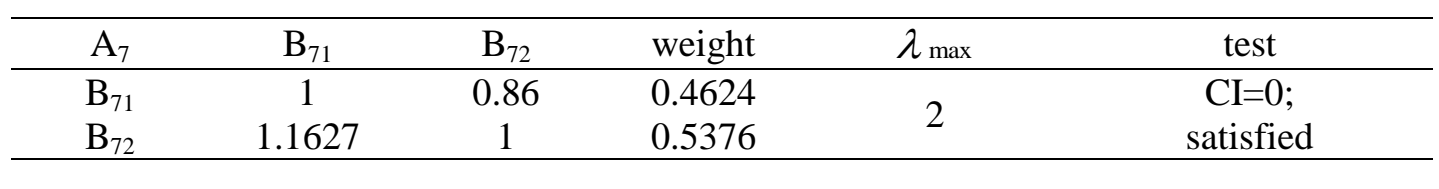

Table 4-10. Indicators Weights of Layer A8-B

\begin{tabular}{cccccc}
\hline $\mathrm{A}_{8}$ & $\mathrm{~B}$ & $\mathrm{~B}_{82}$ & weight & $\lambda$ max & test \\
\hline $\mathrm{B}_{81}$ & 1 & 0.6667 & 0.4000 & 2 & $\mathrm{CI}=0 ;$ \\
$\mathrm{B}_{82}$ & 1.5 & 1 & 0.6000 & 2 & satisfied \\
\hline
\end{tabular}

Table 4-11. Indicators Weights Corresponding To the First Class

\begin{tabular}{c|c|c}
\hline \multirow{4}{*}{ first class } & second class & third class \\
\cline { 2 - 3 } $\begin{array}{c}\text { Indicator } \\
\text { system of } \\
\text { construction } \\
\text { project } \\
\text { performance } \\
\text { evaluation } \\
(\mathrm{O})\end{array}$ & $\left(\mathrm{A}_{1}\right) 0.0902$ & $\left(\mathrm{~B}_{11}\right) 0.0401$ \\
\cline { 2 - 3 } & $\left(\mathrm{A}_{2}\right) 0.0813$ & $\left(\mathrm{~B}_{12}\right) 0.0501$ \\
\cline { 3 - 3 } & \multirow{2}{*}{$\left(\mathrm{A}_{3}\right) 0.1585$} & $\left(\mathrm{~B}_{22}\right) 0.0474$ \\
\cline { 3 - 3 } & \multirow{2}{*}{$\left(\mathrm{A}_{4}\right) 0.1249$} & $\left(\mathrm{~B}_{31}\right) 0.0865$ \\
\cline { 3 - 3 } & \multirow{2}{*}{$\left(\mathrm{A}_{5}\right) 0.1653$} & $\left(\mathrm{~B}_{32}\right) 0.0720$ \\
\cline { 3 - 3 } & & $\left(\mathrm{B}_{42}\right) 0.0571$ \\
\hline
\end{tabular}




\begin{tabular}{l|l|l}
\hline \multirow{2}{*}{$\left(\mathrm{A}_{6}\right) 0.1164$} & $\left(\mathrm{~B}_{61}\right) 0.0656$ \\
\cline { 3 - 3 } & \multirow{2}{*}{$\left(\mathrm{A}_{7}\right) 0.1129$} & $\left(\mathrm{~B}_{62}\right) 0.0508$ \\
\cline { 3 - 3 } & \multirow{2}{*}{$\left(\mathrm{A}_{8}\right) 0.1505$} & $\left(\mathrm{~B}_{71}\right) 0.0522$ \\
\cline { 3 - 3 } & & $\left(\mathrm{B}_{72}\right) 0.0607$ \\
\cline { 3 - 3 } & & $\left(\mathrm{B}_{81}\right) 0.0602$ \\
\hline
\end{tabular}

(2) Indicators weights by entropy weight method

Based on the indicator system and indicator data from three projects, the entropy weight method is applied to determine indicators weights, as the Table 4-12 shows.

Table 4-12. Indicators Weights by Entropy Weight Method

\begin{tabular}{ccccccc}
\hline indicators & $\mathrm{P} 1$ & $\mathrm{P} 2$ & $\mathrm{P} 3$ & $\mathrm{e}_{\mathrm{i}}$ & $\mathrm{g}_{\mathrm{i}}$ & $\mathrm{w}_{\mathrm{i}}$ \\
\hline $\mathrm{B}_{11}$ & 60 & 100 & 80 & 0.9803 & 0.0197 & 0.0570 \\
$\mathrm{~B}_{12}$ & 74.2857 & 100 & 60 & 0.9798 & 0.0202 & 0.0585 \\
$\mathrm{~B}_{21}$ & 100 & 80 & 60 & 0.9809 & 0.0191 & 0.0553 \\
$\mathrm{~B}_{22}$ & 80 & 100 & 60 & 0.9786 & 0.0214 & 0.0619 \\
$\mathrm{~B}_{31}$ & 60 & 86.6667 & 100 & 0.9808 & 0.0192 & 0.0556 \\
$\mathrm{~B}_{32}$ & 80 & 100 & 60 & 09795 & 0.0205 & 0.0593 \\
$\mathrm{~B}_{41}$ & 100 & 93.3333 & 60 & 0.9794 & 0.0206 & 0.0598 \\
$\mathrm{~B}_{42}$ & 75.3846 & 100 & 60 & 0.9801 & 0.0199 & 0.0577 \\
$\mathrm{~B}_{43}$ & 100 & 90 & 60 & 0.9802 & 0.0198 & 0.0575 \\
$\mathrm{~B}_{51}$ & 60 & 100 & 68.8889 & 0.9777 & 0.0223 & 0.0646 \\
$\mathrm{~B}_{52}$ & 60 & 80 & 100 & 0.9792 & 0.0208 & 0.0603 \\
$\mathrm{~B}_{61}$ & 60 & 100 & 74.5455 & 0.9799 & 0.0201 & 0.0583 \\
$\mathrm{~B}_{62}$ & 75 & 100 & 60 & 0.9800 & 0.0200 & 0.0580 \\
$\mathrm{~B}_{71}$ & 100 & 76 & 60 & 0.9802 & 0.0198 & 0.0573 \\
$\mathrm{~B}_{72}$ & 80 & 100 & 60 & 0.9807 & 0.0193 & 0.0560 \\
$\mathrm{~B}_{81}$ & 715790 & 100 & 60 & 0.9789 & 0.0211 & 0.0611 \\
$\mathrm{~B}_{82}$ & 60 & 80 & 100 & 0.9787 & 0.0213 & 0.0618 \\
\hline
\end{tabular}

(3) Indicators combmation weights

The weights of subjective and objective weight methods for the combination weight are calcu/ated by lagrange algorithm, and the result is shown in Table 4-13.

Table 4-13. Indicators Combination Weight

\begin{tabular}{cccccccc}
\hline indicators & weight & indicators & weight & indicators & weight & indicators & weight \\
\hline $\mathrm{B}_{12}$ & 0.0422 & $\mathrm{~B}_{32}$ & 0.0704 & $\mathrm{~B}_{52}$ & 0.0926 & $\mathrm{~B}_{81}$ & 0.0603 \\
$\mathrm{~B}_{12}$ & 0.0511 & $\mathrm{~B}_{41}$ & 0.0574 & $\mathrm{~B}_{61}$ & 0.0647 & $\mathrm{~B}_{82}$ & 0.0867 \\
$\mathrm{~B}_{21}$ & 0.0396 & $\mathrm{~B}_{42}$ & 0.0440 & $\mathrm{~B}_{62}$ & 0.0517 & & \\
$\mathrm{~B}_{22}$ & 0.0461 & $\mathrm{~B}_{43}$ & 0.0298 & $\mathrm{~B}_{71}$ & 0.0528 & & \\
$\mathrm{~B}_{31}$ & 0.0826 & $\mathrm{~B}_{51}$ & 0.0677 & $\mathrm{~B}_{72}$ & 0.0601 & & \\
\hline
\end{tabular}

\subsection{The result of TOPSIS}

Weighted judgment matrix can be calculated by the indicators data after processing and indicators combination weights, as the Table 4-14 shows. 
Table 4-14. Weighted Judgment Matrix

\begin{tabular}{clcl}
\hline indicators & \multicolumn{3}{c}{ weighted judgment matrix } \\
\hline $\mathrm{B}_{11}$ & 2.5325 & 4.2209 & 3.7604 \\
$\mathrm{~B}_{12}$ & 3.7996 & 5.1148 & 3.0689 \\
$\mathrm{~B}_{21}$ & 3.2428 & 3.9634 & 2.3780 \\
$\mathrm{~B}_{22}$ & 2.7688 & 3.2722 & 4.6146 \\
$\mathrm{~B}_{31}$ & 4.9586 & 7.0465 & 8.2644 \\
$\mathrm{~B}_{32}$ & 5.1638 & 7.0415 & 4.2249 \\
$\mathrm{~B}_{41}$ & 5.7437 & 5.3608 & 3.4462 \\
$\mathrm{~B}_{42}$ & 3.3139 & 4.3959 & 2.6376 \\
$\mathrm{~B}_{43}$ & 2.9756 & 2.6781 & 1.7854 \\
$\mathrm{~B}_{51}$ & 4.0598 & 6.7663 & 4.6612 \\
$\mathrm{~B}_{52}$ & 5.5557 & 8.6897 & 9.2595 \\
$\mathrm{~B}_{61}$ & 3.8813 & 6.4689 & 4.8223 \\
$\mathrm{~B}_{62}$ & 3.8774 & 5.1699 & 3.1019 \\
$\mathrm{~B}_{71}$ & 5.2836 & 4.0156 & 3.1702 \\
$\mathrm{~B}_{72}$ & 5.2098 & 6.0113 & 3.6068 \\
$\mathrm{~B}_{81}$ & 4.3171 & 8.0312 & 3.6187 \\
$\mathrm{~B}_{82}$ & 5.2046 & & 8.6743 \\
\hline
\end{tabular}

The positive and negative ideal points can be determined by the table above:

$\mathrm{X}^{+}=(4.220951148,3.9634 .4 .6146,8.2644,7.0415,5.7437,4.3959,2.9756,6.7663$,

$9.2595,64689,5.1699,5.2836,6.0113,6.0312,8.6743)$

$\mathrm{X}^{-}=(2.5325,3.0689,2.3780,2.7688,4.9586,4.2249,3.4462,2.6376,1.7854,4.0598$, $5.5557,3.8813,3.1019,3.1702,3.6068,3.6187,5.2046)$

Then, distances 0 th positive, negative ideal points, the similarities with positive ideal point and the sequence of the three projects are shown in Table 4-15.

Table 4-15. The Result of TOPSIS

\begin{tabular}{ccccc}
\hline items & $\mathrm{y}^{+}$ & $\mathrm{y}^{-}$ & $\mathrm{C}_{\mathrm{i}}$ & sequence \\
\hline $\mathrm{P} 1$ & 69.1607 & 17.4411 & 0.2014 & 3 \\
$\mathrm{P} 2$ & 5.6019 & 79.5978 & 0.9342 & 1 \\
$\mathrm{P} 3$ & 52.119 & 42.8471 & 0.4512 & 2 \\
\hline
\end{tabular}

According to the table above, the score of P2 is the highest. And by the methods applied in this paper, the performance levels of three projects are evaluated, in which $\mathrm{P} 2$ ranks first, $\mathrm{P} 3$ second, P1 third. 


\section{Conclusions}

This paper takes the drawback that the project performance has great influence on enterprise performance into consideration, through the introduction of financial indicators, indicators of internal processes, learning and development indicators, to build a new comprehensive performance evaluation index system for construction projects. Based on this, performance indicators data of construction project is collected and then further processed, which lays the foundation for determining indicators weights. At last, TOPSIS is applied to comprehensively evaluate the projects performance levels. With living examples, the indicator system, combination weight method and comprehensive evaluation method are verified feasible. Judging from the raw data, the comprehensive performance condition of P2 is better, while the evaluation result of $\mathrm{P} 2$ ranks the first, consistent with the reality. Therefore, the evaluation methods introduced in this paper will provide reference, for project performance evaluation. However, the relative importance of indicators in eigenvalue method is from experts scoring, which is inevitably subjective. So how to reduce the experts' subjective influence to the minimum and ensure a reasonable, real evaluation result still need further research.

\section{References}

[1] Herman and Aggis, "Performance management", Beijing China Renmin University Press, (2008).

[2] Y.H. Fu and Y.L. Xu, "Performance management (Second Edition)", Shanghai: Fudan University Press, (2008).

analysis of Projects' performance in

[3] E.K. Zavadskasn, T. Vilutiene and Z. Turskis, Multi-criteria analysis of Project
construction", Archives of Civil and Mechanteal Engineering-(2014), pp. 114-121.

[4] T.J. Wang and Y.B. Lai, "Study on the Performance Evaluation Index System of the Highway Construction Project", Highway traffic science and Technology (Technology Edition), no. 09, (2008), 186-191.

[5] C. Ngacho and D. Das, "A performance evaluation framework of development projects: An empirical study of Constituency Development Fund construction projects in Kenya", International Journal of Project Management, vol. 32, no. 3, (2008), p. 492-507.

[6] Y.H. Sun and H. Luo, "Performance Appraisal Quantitative Management", Beijing: People's Posts and Telecommunications Press, (2008), pp 524-526.

[7] H.T. Wen and C.P. Ren, "A New Study of Non-measurement in Evaluation of Enterprise's Performance", On Economic Problems, no. 6, (2011), pp. 61-65.

[8] H.B. Lv, "The Efficacy Coefficient Method in the Evaluation of Enterprise Performance", Inner Mongol a Science Technology and Economy, no. 9, (2009), pp. 69-71.

[9] W.J. Qu and X.Y. Fang Assessment of black-start modes based on entropy value method and principal component analysis". Power System Protection and Control, vol. 42, no., (2014)8, pp. 22-27.

[10] G.X. Song and D.L Yang, "Combination weighting approach based on the decision-maker's preference and consistency of weighting methods", Systems Engineering and Electronics, vol. 26, no. 9, (2004), pp. 1226-1230.

[11] X.X. Luo and S.H. Peng, "Research on the Vendor Evaluation and Selection Based on AHP and TOPSIS in Green Supply Chain”, Soft science, vol. 25, no. 2, (2011), pp. 53-56. 
International Journal of Hybrid Information Technology

Vol. 9, No.12 (2016)

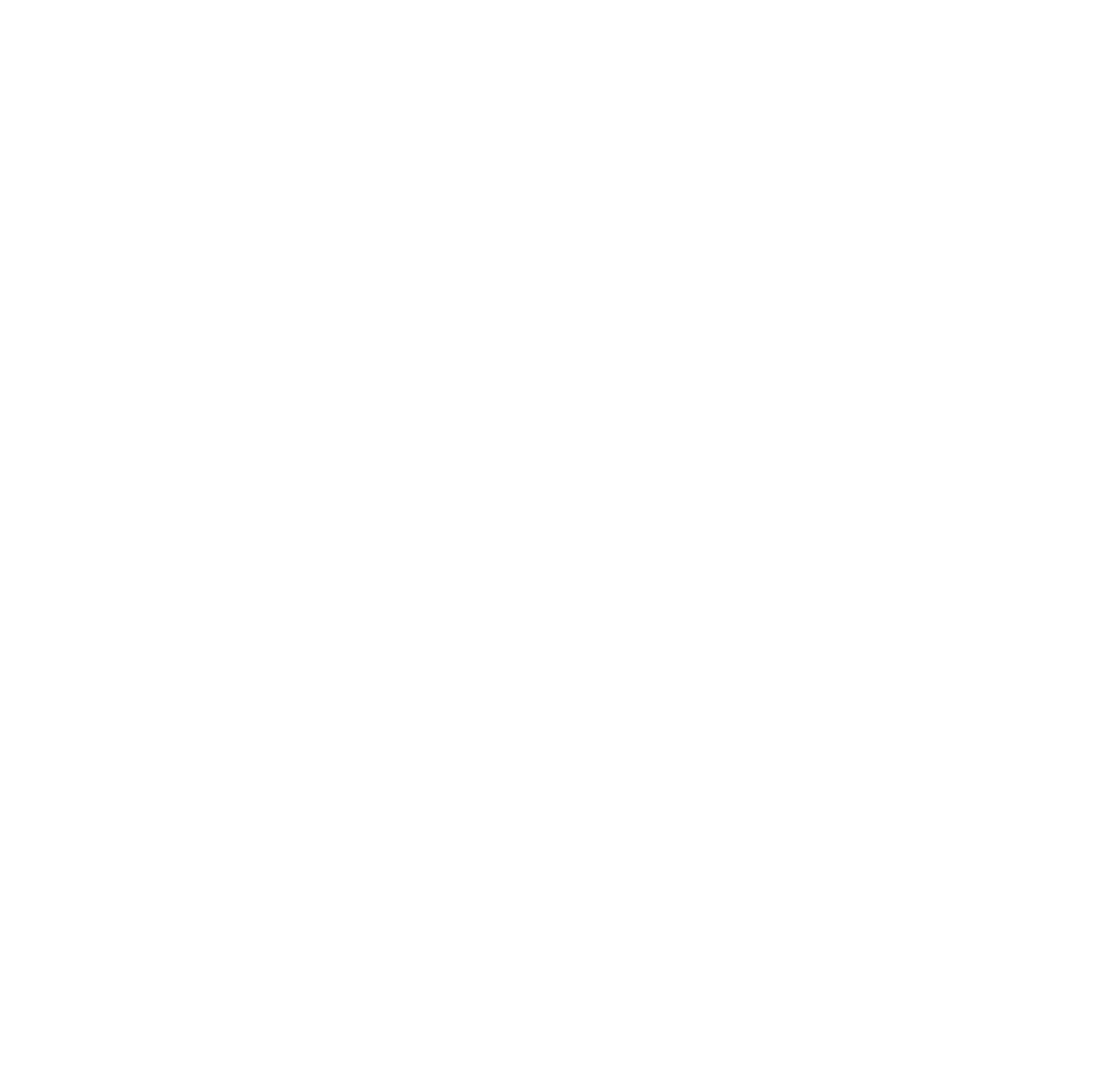

